\title{
A digital cmos sequential circuit model for bio-cellular adaptive immune response pathway using phagolysosomic digestion: a digital phagocytosis engine
}

\author{
Sayed Mohammad Rezaul Hasan
}

Center for Research in Analog and VLSI Microsystem Design, School of Engineering and Advanced Technology, Massey University, Albany, New Zealand.

Email: hasanmic@massey.ac.nz

Received 26 February 2010; revised 11 March 2010; accepted 16 March 2010.

\begin{abstract}
Living systems have to constantly counter micro-organisms which seek parasitic existence by extracting nutrition (amino acids) from the host. Phagocytosis is the ingestion of micro-creatures by certain cells of living systems for counter nutrition (breakdown of the micro-creature into basic components) as part of cellular adaptive immune response. These particular cells are called phagocytes, all of which are different types of white blood cells or their derivatives. Phagocytes are activated by certain components of the micro-creatures which act as an antigen, generating antibody secretion by the phagocyte. This paper develops a digital CMOS circuit model of phagocytosis: the immune response biochemical pathway of a phagocyte. A micro-sequenced model has been developed where the different stages in phagocytosis are modeled as different states clocked by circadian time intervals. The model converts the bio-chemical immune system digestive pathway into a cascade of CMOS multi-step logical transformations from micro-creature ingestion to the secretion of indigestible residuals. This modeling technique leads to the understanding of cellular immune deficiency diseases of living systems in the form of logical (electrical) faults in a circuit.
\end{abstract}

Keywords: Systems Biology; CMOS Circuit; Phagocytosis; Silicon Mimetic

\section{INTRODUCTION}

Looking at bio-chemical pathways of biological systems from a micro-electronic circuit diagram perspective is an interesting analytical paradigm in developing the convergence of biosciences, biotechnology and electrical engineering. In an effort towards understanding the biochemical functions of living systems at molecular interaction level researchers working in the developing field of systems biology $[1,2]$ have endeavored to provide models that integrate the molecular interactions between proteins [3], enzymes [4,5], DNA [6], RNA [4], ions etc. within individual bio-cells of different kinds and their derivatives.

Immune response is one of the most fundamental biochemical activity of living systems. Micro-creatures constantly harboring towards living systems for parasitic existence are subjected to counter nutrition mechanisms of certain type of immune system cells, e.g., white blood cells or their derivatives usually known as phagocytes. This process of immune response is know as phagocytosis. It is a cascade of molecular interactions within the phagocyte which result in the breakdown of the micro-creature into its basic components, parts of which are recycled (digested) for nutrition and the rest eliminated from the system as residual waste. Circuit theoretic techniques of modeling this biochemical immune system pathway within a phagocyte compared to other mathematical modeling techniques $[7,8]$ is the central theme of this paper. In recently published papers [9-11] this author described how the states of DNA protein interactions within the bio-cellular operations can be modeled using integrated circuits (silicon mimetic model $[12,13])$. In addition, models for mitochondrial respiration related electron transfer pathway [14], and cell signaling pathway using G-Protein and Phosphorylation cascade [15] has been reported by this author. These models based on integrated circuits are amenable to the large variety of mature simulation tools [16] available in the Very Large Scale Integration (VLSI) Computer aided design (CAD) arena. This type of modeling thus enhances the knowledge required for the realization of the "dream" of designed biochemical pathways and gene circuits [12] with revolutionary outcomes for gene and cell therapy ("nano-medicine"). In this work a digital CMOS [17] micro-sequenced model for phagocytosis has been developed where the sequence of biochemical processing stages are clocked by circadian time (hours) 
[7] intervals.

\section{PHAGOLYSOSOMIC IMMUNE RESPONSE BIO-CHEMICAL PATHWAY}

Infection of living systems by micro-creatures results in various types of white blood cells becoming phagocytes and moving into infected tissue. These phagocytes enlarge and develop into a macrophage engulfing and devouring micro-creatures in a counter nutrition effort. Figure 1(a) shows the microphotograph of such a macrophage digesting micro-creatures (red bacterium). Figure 1(b) shows the mechanism of phagocytosis in terms of the bio-chemical pathway in a phagocyte. The bio-chemical pathway of Phagocytosis [4,5] can be di-

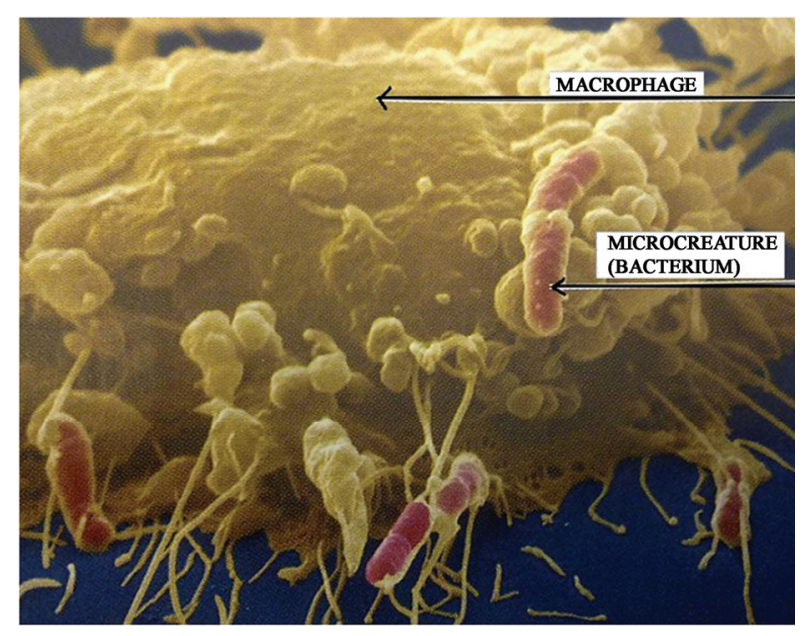

(a)

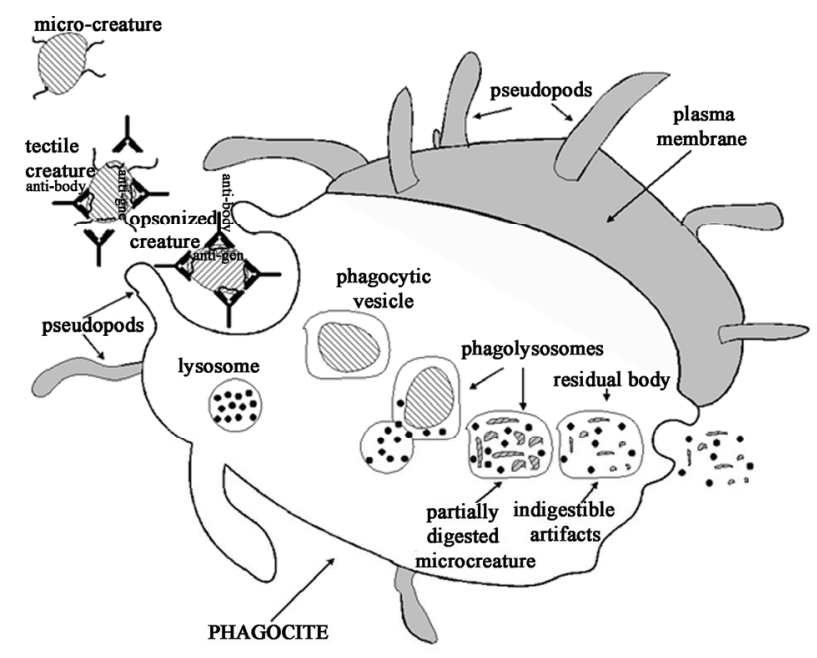

(b)

Figure 1. (a) Photomicrograph [5] of phagocytic digestion (microphage) of red micro-creatures (bacterium); (b) a schematic illustration of the mechanism of phagocytosis (biochemical pathway) in a phagocyte. vided into several states such as chemotaxis (or phototaxis), adherence, opsonization, ingestion, digestion and residue ejection. Chemotaxis (or, phototaxis) by chemical (or optical) stimuli is the mechanism of approach through "run" and "tumble" of micro-creatures towards favorable host living systems. Phagocytes are attracted by the micro-creatures through their antigenic components, resulting in the release of antibody serum proteins that opsonize the microcreatures. Opsonized microcreatures then easily adhere to the plasma membrane of the phagocyte which is referred to as a state of adherence. After adherence, there is ingestion, whereby, the phagocyte extend its flagella type "arms" called pseudopods which surround and then engulf the microcreature. Once ingested, the surrounding pseudopods fuse and enclose the micro-creature in a fluid sack called "phagosome" or phagocytic vesicle. The membrane of this vesicle has enzymes which pump hydrogen ions $\left(\mathrm{H}^{+}\right)$into the vesicle, thereby reducing the $\mathrm{pH}$ to around 4 , so that hydrolytic enzymes can be activated for the breakdown of the micro-creature. The next stage of phagocytosis is the digestive pathway which begins with the phagosome "pinching off" from the plasma membrane and entering the cytoplasm. Inside the cytoplasm the phagosomes attach with lysosome sacks containing digestive enzymes and microbcidal substances. On attachment, the membranes of lysosome and phagosme merge forming a larger composite sack called phagolysosome. The degenerative components inside the phagolysosome take only sub-circadian time interval (less than an hour) to completely breakdown ("kill") micro-creatures inside it. This digestive pathway contains several main and subprocesses. Lysosomic enzyme lysozyme directly attacks the cell-wall of the micro-creature and initiates the hydrolysis of the cell-wall. A host of other lysosomic enzymes are also active at the same time, so that the microcreatures macro-components are disintegrated, such as its lipids by the enzyme lipase, its proteins by protease, its ribonucleic acids by ribonuclease, and, its deoxyribonucleic acids by deoxyribonuclease. Lysosomes also contain certain enzymes which can initiate a process known as oxidative burst which result in toxic oxygen products such as super oxide radical $\left(\mathrm{O}_{2}^{-}\right)$, hydrogen per oxide $\left(\mathrm{H}_{2} \mathrm{O}_{2}\right)$, hydroxyl radical $(\mathrm{OH} \bullet)$ and singlet oxygen $\left({ }^{1} \mathrm{O}_{2}^{-}\right)$. Other lysosomic enzymes combine with these toxic oxygen products to produce secondary microbcides which hydrolyze and breakdown the microcreatures. For instance, the enzyme myeloperoxidase (MY) converts chlorine ions $\left(\mathrm{Cl}^{-}\right)$and hydrogen per oxide $\left(\mathrm{H}_{2} \mathrm{O}_{2}\right)$ into highly toxic hypochlorous acid $(\mathrm{HOCl})$ which contain the well-known anti-microbial 
agent hypochlorous ions.

\section{A MICRO-SEQUENCED MODEL OF PHAGOCYTIC BIOCHEMICAL PATHWAY}

A silicon mimetic [11] model of the bio-chemical pathway of phagocytosis has been developed and is shown in Figure 2. The discussion in the previous section indicates the existence of many intermediate steps in the biochemical digestive pathway of phagocytosis whose proper co-ordination is an important factor in the functional phagocyte of living systems. Similar to the concept introduced in [15], the intermediate steps in the bio-chemical path of phagocytic digestion of microcreatures can be modeled as states in Delay flip-flops (Registers) which indicate the states of molecular interactions (binding, hydrolysis and breakdown) that constitute the behavior of the phagocyte. Using this modeling technique malfunction in the immune system (immune deficiency syndrome: cause of numerous diseases) can be conveniently modeled as circuit faults, such as, outputs of logic gates or flip-flops (registers) are stuck at logic " 0 " or at logic " 1 ", thus unifying the approach to solving faults in electronic or biological circuits (in this case the biological circuit of the immune response sys tem). At any time-instant $n$, presence of Gram positive (GP) or Gram negative (GN) micro-creatures in close proximity to the phagocyte is stored as $\mathrm{ul}(\mathrm{n})$ in the D-FF_1. The presence of chemo-tectile micro-creatures due to the presence of chemical signals is stored as $\mathrm{u} 2(\mathrm{n})$ in the D-FF_2. On the other hand, the presence of phototectile micro-creature due to the presence of optical signals is stored as $\mathrm{u} 3(\mathrm{n})$ in the D-FF_3. The presence of chemo-tectile or phototectile micro-creature opsonized by anti-body serum protein (SP) is stored as $\mathrm{u} 4(\mathrm{n})$ in the D-FF 4. The presence of ingested micro-creatures engulfe $\bar{d}$ by pseudopods (PP) is stored as u5(n) in the D-FF_5. The state of the ingested micro-creatures within phagosomes with $\mathrm{H}^{+}$ions pumped inside the phagocytic vesicle is indicated by $\mathrm{u} 6(\mathrm{n})$ in the D-FF_6. The "pinching off" of phagosome from the plasma membrane and entering the cytoplasm is registered as $\mathrm{u} 7(\mathrm{n})$ in D-FF_7. The attachment and merger of lysosome with the phagosome in the phagolysosome, and the resulting state of the digestive degradation of the microcreatures is represented by,

$$
\mathrm{u} 14(\mathrm{n})=\sum_{\mathrm{m}=10}^{13} \mathrm{um}(\mathrm{n}-1)
$$

The hydrolysis of micro-creature inside the phagolysosome due to hypochloric acid (a byproduct of the oxidative burst) is indicated by the state $\mathrm{u} 8(\mathrm{n})$ stored in the D-FF_8. The breakdown of the micro-creature's cellwall by the enzyme lysozyme (LYE) is indicated by the state $\mathrm{u} 9(\mathrm{n})$ in the D-FF_9. The breakdown of lipids in- side the degenerated micro-creatures by the lysosomic enzyme lipase is indicated by the state $\mathrm{u} 10(\mathrm{n})$ stored in D-FF_10. Next, the breakdown of the bacterial proteins inside the degenerated microbe by the lysosomic enzyme protease is indicated by the state u11(n) stored in D-FF_11. The breakdown of the bacterial ribonucleic acids inside the degenerated microbe by the lysosomic enzyme ribonuclease (RNE) is indicated by the state u12(n) stored in D-FF_12. And, finally the breakdown of the bacterial DNA by the lysosomic enzyme deoxyribonuclease (DNE) is indicated by the state $u 13(n)$ stored in D-FF_13. Based on the micro-step sequenced model of Figure 2, the following discrete-time state equations can be written for the phagocytic digestive pathway:

$$
\begin{aligned}
& \mathrm{u} 1(\mathrm{n})=\mathrm{GP}+\mathrm{GN} \\
& \mathrm{u} 2(\mathrm{n})=\mathrm{CS} \times \mathrm{ul}(\mathrm{n}-1) \\
& \mathrm{u} 3(\mathrm{n})=\mathrm{OS} \times \mathrm{ul}(\mathrm{n}-1) \\
& \mathrm{u} 4(\mathrm{n})=[\mathrm{u} 3(\mathrm{n}-1)+\mathrm{u} 2(\mathrm{n}-1)] \times \mathrm{SP} \\
& \mathrm{u} 5(\mathrm{n})=\mathrm{u} 4(\mathrm{n}-1) \times \mathrm{pp} \\
& \mathrm{u} 6(\mathrm{n})=\mathrm{u} 5(\mathrm{n}-1) \times \mathrm{H}^{+} \\
& \mathrm{u} 7(\mathrm{n})=\mathrm{u} 6(\mathrm{n}-1) \\
& \mathrm{u} 8(\mathrm{n})=\left[\mathrm{u} 7(\mathrm{n}-1) \times\left\{\mathrm{MY} \times \mathrm{Cl}^{-} \times\left(\mathrm{LE} 1 \times \mathrm{H}_{2} \mathrm{O}\right)\right\}\right] \\
& \mathrm{u} 9(\mathrm{n})=[\mathrm{u} 7(\mathrm{n}-1) \times \mathrm{LYE}] \\
& \mathrm{u} 10(\mathrm{n})=[\mathrm{u} 8(\mathrm{n}-1)+\mathrm{u} 9(\mathrm{n}-1)] \times \mathrm{LPE} \\
& \mathrm{u} 11(\mathrm{n})=[\mathrm{u} 8(\mathrm{n}-1)+\mathrm{u} 9(\mathrm{n}-1)] \times \mathrm{PTE} \\
& \mathrm{u} 12(\mathrm{n})=[\mathrm{u} 8(\mathrm{n}-1)+\mathrm{u} 9(\mathrm{n}-1)] \times \mathrm{RNE} \\
& \mathrm{u} 13(\mathrm{n})=[\mathrm{u} 8(\mathrm{n}-1)+\mathrm{u} 9(\mathrm{n}-1)] \times \text { DNE } \\
& \mathrm{u} 14(\mathrm{n})=[\mathrm{u} 10(\mathrm{n}-1)+\mathrm{u} 11(\mathrm{n}-1) \\
&\quad+\mathrm{u} 12(\mathrm{n}-1)+\mathrm{u} 13(\mathrm{n}-1)]
\end{aligned}
$$

Modeling immune response deficiency as electrical faults: Using these circuit model immune deficiency diseases can be modeled as electrical faults. For example, if the serum protein (anti-body) is not produced, the invading micro-creatures cannot be engulfed, and, the state at u(4) will be stuck at " 0 ", resulting in all the down-stream digestive degradation pathway states being stuck at " 0 ", i.e., becomes non-functional. The solutions can then be designed in terms of CMOS circuit functionality and converted into the equivalent biochemical solution (" $n a$ no-medicine").

\section{MICRO-SEQUENCED PHAGOCYTE PATHWAY STATES AND SILICON MIMETIC SIGNAL TRANSDUCTION RESULTS}

Figure 3 displays how the immune system response 


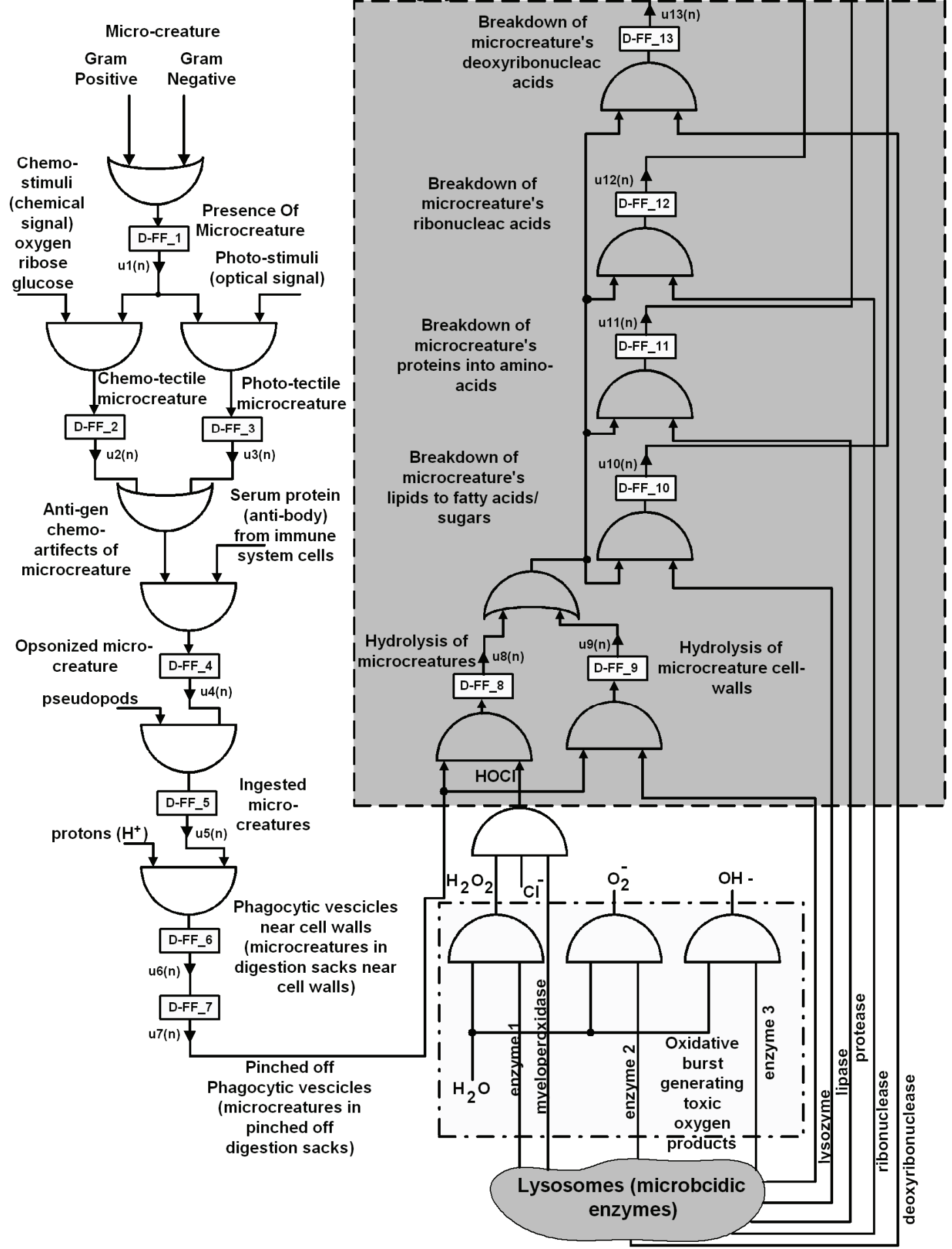

Figure 2. A micro-sequenced digital CMOS model of the bio-chemical pathway of phagocytosis using logic gates and D-flip-flops. 
bio-chemical events form a pipeline through the silicon mimetic model of phagocytosis in a digital CMOS micro-sequenced logic simulation process. It also shows the sequence of intermediate states (D flip-flop states) corresponding to whether a certain bio-chemical state is activated. The sequence of molecular interactions is con- sidered to be taking place in the circadian time-scale (hours or few minutes). The D flip-flops are thus driven by a clock with circadian time period. Figure 3 shows molecular events occurring over 24 circadian time peri ods during which micro-creatures (bacteria or microbes) arrive towards phagocytes until the period $n=8$. This

A micro-step sequence for phagocytosis

\begin{tabular}{|c|c|c|c|c|c|c|c|c|c|c|c|c|}
\hline \multirow{2}{*}{$\begin{array}{c}\text { Path-way } \\
\text { stste }\end{array}$} & \multicolumn{12}{|c|}{ Circadian Time-instant } \\
\hline & $\mathrm{n}=\mathbf{0}$ & $\mathrm{n}=1$ & $\mathbf{n}=\mathbf{2}$ & $\mathrm{n}=\mathbf{3}$ & $n=4$ & $n=5$ & $n=6$ & $\mathrm{n}=7$ & $\mathrm{n}=\mathbf{8}$ & $\mathbf{n}=\mathbf{9}$ & $\mathrm{n}=10$ & $\mathrm{n}=11$ \\
\hline D-FF_1 & RESET & microb & microb & microb & microb & microb & microb & microb & microb & 0 & 0 & 0 \\
\hline D-FF_2 & RESET & 0 & 1 & 1 & 1 & 1 & 1 & 1 & 1 & 1 & 0 & 0 \\
\hline D-FF_3 & RESET & 0 & 1 & 1 & 1 & 1 & 1 & 1 & 1 & 1 & 0 & 0 \\
\hline D-FF 4 & RESET & 0 & 0 & 1 & 1 & 1 & 1 & 1 & 1 & 1 & 1 & 0 \\
\hline D-FF_5 & RESET & 0 & 0 & 0 & 1 & 1 & 1 & 1 & 1 & 1 & 1 & 1 \\
\hline D-FF_6 & RESET & 0 & 0 & 0 & 0 & 1 & 1 & 1 & 1 & 1 & 1 & 1 \\
\hline D-FF_7 & RESET & 0 & 0 & 0 & 0 & 0 & 1 & 1 & 1 & 1 & 1 & 1 \\
\hline D-FF_8 & RESET & 0 & 0 & 0 & 0 & 0 & 0 & 1 & 1 & 1 & 1 & 1 \\
\hline D-FF_9 & RESET & 0 & 0 & 0 & 0 & 0 & 0 & 1 & 0 & 1 & 1 & 1 \\
\hline D-FF_10 & RESET & 0 & 0 & 0 & 0 & 0 & 0 & 0 & 0 & 1 & 1 & 1 \\
\hline D-FF_11 & RESET & 0 & 0 & 0 & 0 & 0 & 0 & 0 & 0 & 1 & 1 & 1 \\
\hline D-FF_12 & RESET & 0 & 0 & 0 & 0 & 0 & 0 & 0 & 0 & 1 & 1 & 1 \\
\hline D-FF_13 & RESET & 0 & 0 & 0 & 0 & 0 & 0 & 0 & 0 & 1 & 1 & 1 \\
\hline D-FF_14 & RESET & 0 & 0 & 0 & 0 & 0 & 0 & 0 & 0 & 1 & 1 & 1 \\
\hline
\end{tabular}

(a)

A micro-step sequence for phagocytosis(contd.)

\begin{tabular}{|c|c|c|c|c|c|c|c|c|c|c|c|c|}
\hline \multirow{2}{*}{$\begin{array}{l}\text { Path-way } \\
\text { stste }\end{array}$} & \multicolumn{12}{|c|}{ Circadian Time-instant } \\
\hline & $\mathrm{n}=12$ & $\mathrm{n}=13$ & $\mathrm{n}=14$ & $\mathrm{n}=15$ & $\mathrm{n}=16$ & $\mathrm{n}=17$ & $\mathrm{n}=18$ & $\mathrm{n}=19$ & $\mathrm{n}=\mathbf{2 0}$ & $\mathrm{n}=21$ & $\mathrm{n}=22$ & $n=23$ \\
\hline D-FF_1 & 0 & microb & microb & microb & microb & 0 & 0 & 0 & 0 & 0 & 0 & 0 \\
\hline D-FF_2 & 0 & 0 & 1 & 1 & 1 & 1 & 0 & 0 & 0 & 0 & 0 & 0 \\
\hline D-FF 3 & 0 & 0 & 1 & 1 & 1 & 1 & 0 & 0 & 0 & 0 & 0 & 0 \\
\hline D-FF 4 & 0 & 0 & $\overline{0}$ & 1 & 1 & 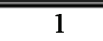 & 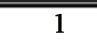 & 0 & 0 & 0 & 0 & 0 \\
\hline D-FF_5 & 0 & 0 & 0 & 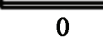 & $\overline{1} 1$ & 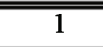 & 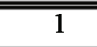 & 1 & 0 & 0 & 0 & 0 \\
\hline D-FF_6 & 1 & 0 & 0 & 0 & 0 & 1 & 1 & 1 & 1 & 0 & 0 & 0 \\
\hline D-FF_7 & 1 & 1 & 0 & 0 & 0 & 0 & 1 & 1 & 1 & 1 & 0 & 0 \\
\hline D-FF_8 & 1 & 1 & 1 & 0 & 0 & 0 & 0 & 1 & 1 & 1 & 1 & 0 \\
\hline D-FF_9 & 1 & 1 & 1 & 0 & 0 & 0 & 0 & $\bar{~} 1$ & $\overline{1} 1$ & 1 & 1 & 0 \\
\hline D-FF_10 & 1 & 1 & 1 & 1 & 0 & 0 & 0 & 0 & 1 & 1 & 1 & 1 \\
\hline D-FF_11 & 1 & 1 & 1 & 1 & 0 & 0 & 0 & 0 & 1 & 1 & 1 & 1 \\
\hline D-FF_12 & 1 & 1 & 1 & 1 & 0 & 0 & 0 & 0 & 1 & 1 & 1 & 1 \\
\hline D-FF_13 & 1 & 1 & 1 & 1 & 0 & 0 & 0 & 0 & 1 & 1 & 1 & 1 \\
\hline D-FF_14 & 1 & 1 & 1 & 1 & 1 & 0 & 0 & 0 & 0 & 1 & 1 & 1 \\
\hline
\end{tabular}

(b)

Figure 3. Sequence of intermediate steps (D flip-flop states) in the phagocytic bio-chemical pathway, (a) for circadian time-instants $n$ $=0$ to $\mathrm{n}=11$; and (b) for circadian time-instants $\mathrm{n}=12$ to $\mathrm{n}=23$. 
causes the immune response pathway to activate. This results in the presence of either chemo-tectile (D-FF_2) or photo-tectile (D-FF_3) micro-creatures during the circadian interval $\langle 2,9\rangle$. Also, opsonized microcreatures are present during the interval $\langle 3,10\rangle$, microcreatures are ingested during the interval $\langle 4,11\rangle$, digestive vesicles are formed near the phagocyte membrane during the interval $\langle 5,12\rangle$, vesicles are detached and moves into the cytoplasm during the interval $\langle 6,13\rangle$, phagolysosome is formed and the microcreature is hydrolyzed (state in D-FF_8) and microcreature cell-wall is hydrolyzed (state in D-FF 9) during the interval $<7,14>$. The breakdown of lipids (state in D-FF_10), proteins (state in D-FF 11), ribonucleic acid (state in D-FF-12) and deoxyribonucleic acid (state in D-FF_13) take place simultaneously in the interval $\langle 8,15\rangle$. The undigested micro-creature artifacts (state in D-FF_14) are removed during the interval $\langle 9,16\rangle$. As the micro-creatures are is not present during the interval $\langle 9,12\rangle$, there is a short pause in the digestive bio-chemical process which is evident from the diagonal zero states in Figure 3(b). Also, beginning the interval $<13,16\rangle$ the presence of a short burst of microcreatures results in a short pipeline of digestive pathway activities (reactions and interactions) that is evident through the diagonal array of " 1 " as shown in Figure 3(b).

\section{CONCLUSIONS}

A digital circuit based model for the phagocytic biochemical digestive pathway in living systems has been developed and discussed in detail. The model corresponds quite well with the immune response phenomenon depicting striking resemblance of CMOS logic circuit (with states in D flip-flops) to states in bio-cellular phenomenon. Compared to mathematical modeling, model derived from analogies with integrated circuit allows VLSI CAD circuit and logic simulators to be conveniently used as a biological simulation program. Hence this work provides an alternative route for further systems biological investigation into more comprehensive integrated circuit models for more extensive biochemical pathways in living systems. This investigation will thus contribute to the desired manipulation of biological processes at the cellular level leading to electrical circuit modeling of diseases and "nano-medicine".

\section{REFERENCES}

[1] Dhar, P.K., Zhu, H. and Mishra, S.K. (2004) Computational approach to systems biology: From fraction to integration and beyond. IEEE Transactions on Nanobioscience, 3(3), 144-152.
[2] Khammash, M. and El-Samad, H. (2004) Systems boilogy: From physiology to gene regulation. IEEE Control Systems Magazine, 24(4), 62-76.

[3] Vaidyanathan, P.P. (2004) Genomics and proteomics: A signal processor's tour. IEEE Circuits and Systems Magazine, 4(4), 6-29.

[4] Campbell, N.A. and Reece, J.B. (2005) Biology. Pearson, San Francisco.

[5] Tortora, G.J., Funke, B.R. and Case, C.L. (2007) Microbiology: An introduction. Pearson Benjamin Cummings, San Francisco.

[6] Watson, J.D. and Crick, F.H.C. (1953) A structure for DNA. Nature, 171(4356), 737-738.

[7] Goldbeter, A. (1995) A model for circadian oscillations in the drosophila period protein. Proceedings of Biological Sciences, 261(1362), 319-324.

[8] Chen, L. and Wang, R. (2006) Designing gene regulatory networks with specified functions. IEEE Transactions on Circuits and Systems-I: Regular Papers, 53(11), 24442450.

[9] Hasan, S.M.R. (2005) A novel CMOS integrated circuit model for cellular DNA-protein regulatory mRNA transcription process. Proceedings of 12th International Conference on Biomedical Engineering, International Federation for Medical and Biological Engineering CD proceedings, Singapore.

[10] Rezaul Hasan, S.M. (2005) A novel integrated circuit model for mRNA transcription in bio-cellular processes," Proceedings of 12th Electronics New Zealand Conference, Manukau, 7-12.

[11] Hasan, S.M.R. (2008) A novel mixed-signal integrated circuit model for DNA-protein regulatory genetic circuits and genetic state machines. IEEE Transactions on Circuits and Systems-I: Regular Papers, 55(5), 1185-1196.

[12] Hasty, J., McMillen, D. and Collins, J.J. (2002) Engineered gene circuits. Nature, 420(14), 224-230.

[13] Simpson, M.L., Cox, C.D., Peterson, G.D. and Sayler, G.S. (2004) Engineering in the biological substrate: Information processing in genetic circuits. Proceedings of the IEEE, 92(5), 848-863.

[14] Hasan, S.M.R. and Ula, N. (2008) Analog CMOS charge model for molecular redox electron-transfer reactions and bio-chemical pathways. Proceedings of International Symposium on Circuits and Systems, Geneva.

[15] Rezaul Hasan, S.M. (2008) A Micro-sequenced CMOS model for cell signaling pathway using G-protein and phosphorylation cascade. International Journal of Intelligent Systems Technologies and Applications, 19(12) 57-62.

[16] Schiek, R.L. and May, E.E. (2003) Development of a massively-parallel, biological circuit simulator. Proceedings of the Computational Systems Bioinformatics, Cambridge, 620-622.

[17] K. Martin, (2000) Digital integrated circuit design. Oxford University Press, Oxford. 